\title{
CÉDULA DE VOTACIÓN: ¿DOCUMENTO O INFORMACIÓN PÚBLICA? LOS CASOS DE MÉXICO Y PERÚ
}

VOTING CERTIFICATE: DOCUMENT OR PUBLIC INFORMATION? THE CASES OF MEXICO AND PERU

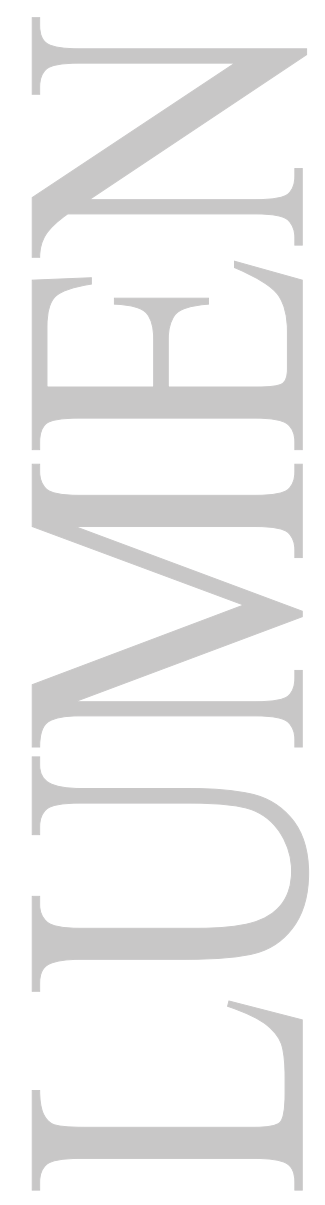




\title{
CÉDULA DE VOTACIÓN: ¿DOCUMENTO O INFORMACIÓN PÚBLICA? LOS CASOS DE MÉXICO Y PERÚ
}

\author{
VOTING CERTIFICATE: DOCUMENT OR PUBLIC INFORMATION? THE \\ CASES OF MEXICO AND PERU
}

Gustavo Romero Umlauff

\begin{abstract}
RESUMEN:
El presente artículo examina una Sentencia dictada por la Sala Superior del Tribunal Electoral del Poder Judicial de la Federación de la República Mexicana en relación las resoluciones definitivas emitidas por la Comisión del Consejo para la Transparencia y Acceso a la Información del Instituto Federal Electoral por las cuales negaron las solicitudes de unos ciudadanos mexicanos a proporcionarles copias de las "boletas electorales" (o "cédulas de votación" tratándose del caso peruano) relativas al proceso electoral por cuanto el resultado de la elección presidencial les causaba reparos sobre el cómputo de los votos y requerían de ellas para contabilizarlas nuevamente.
\end{abstract}

Claro está que la trascendencia académica de resolver aquella demanda no estaba fundamentalmente en revisar el resultado del proceso electoral sino elucidar las características de las "boletas electorales" abordadas en aquella Sentencia en materia de acceso a la información pública y las atribuciones de la Sala Superior del Tribunal Electoral del Poder Judicial de la Federación de la República Mexicana para emitir un pronunciamiento sobre su naturaleza jurídica. Ello, obviamente, no es una cuestión menor pues constituye un excepcional -o quizás- aún el único precedente doctrinario para los países iberoamericanos en materia de documentación electoral.

\section{PALABRAS CLAVES:}

Boletas electorales, acceso a la información, Ley Federal de Transparencia y Acceso a la Información Pública Gubernamental, documento público, principio de la publicidad.

\begin{abstract}
:
This article examines a Judgment issued by the Sala Superior del Tribunal Electoral del Poder Judicial de la Federación de la República Mexicana (Superior Court of the Electoral Tribunal of the Judicial Power of the Federation of the Mexican Republic) in relation to the final resolutions issued by the Commission of the Council for Transparency and Access to Information of the Federal Electoral Institute, which denied the requests of mexican citizens to provide them with copies of the "ballots" (or "ballot papers" in the case of Peru) regarding the electoral process because the results of the presidential election caused them to object to the calculation of the votes and required them to count them again. Of course, the academic importance of resolving that demand was not fundamentally to review the outcome of the electoral process but to elucidate the characteristics of the "ballots" addressed in that judgment in matters of access to public information and powers of the Superior Chamber of the Electoral Court of the Judicial Power of the Federation of the Mexican Republic to issue a ruling on its legal nature. Obviously, this is not a minor issue, since it constitutes an exception - or perhaps - still the only doctrinal precedent for the Ibero-American countries regarding electoral documentation.
\end{abstract}

\section{KEY WORDS:}

Electoral ballots, access to information, Federal Transparency Law and Access to Government Public Information, public document, advertising principle 


\section{INTRODUCCIÓN}

Atendiendo a una invitación para participar en el Seminario Internacional sobre "Temas actuales del derecho a la información pública en materia electoral", organizado por el Centro de Derechos Políticos de la Facultad de Jurisprudencia de la Universidad Autónoma de Coahuila, en coordinación con el Instituto Electoral y de Participación Ciudadana de Coahuila, el Tribunal Electoral del Poder Judicial de la Federación, el Tribunal Electoral del Poder Judicial de Coahuila, el Programa de las Naciones Unidas para el Desarrollo, el Instituto de Derechos Humanos "Bartolomé de las Casas" de la Universidad Carlos III de Madrid, la Universidad de Valladolid, el Instituto Coahuilense de Acceso a la Información Pública y la Asociación de Tribunales y Salas Electorales de la República Mexicana, fuimos encomendados a examinar una Sentencia dictada por la Sala Superior del Tribunal Electoral del Poder Judicial de la Federación de la República Mexicana en relación las resoluciones definitivas emitidas por la Comisión del Consejo para la Transparencia y Acceso a la Información del Instituto Federal Electoral por las cuales negaron las solicitudes de unos ciudadanos mexicanos a proporcionarles copias de las "boletas electorales" (o "cédulas de votación" tratándose del caso peruano) relativas al proceso electoral por cuanto el resultado de la elección presidencial les causaba reparos sobre el cómputo de los votos y requerían de ellas para contabilizarlas nuevamente.

Claro está que la trascendencia académica de resolver aquella demanda no estaba fundamentalmente en revisar el resultado del proceso electoral sino elucidar las características de las "boletas electorales" abordadas en aquella Sentencia en materia de acceso a la información pública y las atribuciones de la Sala Superior del Tribunal Electoral del Poder Judicial de la Federación de la República Mexicana para emitir un pronunciamiento sobre su naturaleza jurídica. Ello, obviamente, no es una cuestión menor pues constituye un excepcional -o quizás- aún único precedente doctrinario para los países iberoamericanos en materia de documentación electoral.

Aun cuando el trabajo inicial sólo planteó la temática jurisprudencial mexicana, con posterioridad consideramos que podría constituir un mejor aporte a la academia, ahondar el análisis teniendo en cuenta algunas referencias legislativas peruanas sobre las mismas materias.

\section{LA CUESTIÓN DE LA SENTENCIA DE FECHA 25 DE ABRIL DE 2007 (SUP-JDC-10/2007 Y SUP-JDC-88/2007 ACUMULADOS).}

La cuestión apunta a examinar sólo un extremo de la Sentencia de fecha 25 de abril de 2007 (SUP-JDC-10/2007 y SUP-JDC-88/2007 Acumulados) ${ }^{1}$ dictada por la Sala Superior del Tribunal Electoral del Poder Judicial de la Federación de la República Mexicana y, acaso, primordial del caso; esto es, acerca de las particularidades legales de las "boletas electorales" así como las atribuciones de la Sala Superior del Tribunal Electoral del Poder Judicial de la Federación para emitir un pronunciamiento sobre la naturaleza jurídica de ellas.

Dicha Sentencia falla sobre las impugnaciones interpuestas por los ciudadanos José Daniel Lizárraga Méndez y Delia Angélica Ortiz Trujillo contra las resoluciones definitivas emitidas por la Comisión del Consejo para la Transparencia y Acceso a la Información del Instituto Federal Electoral por las cuales negaron el pedido a proporcionarles copias de las "boletas electorales" relativas al proceso federal electoral correspondiente al año dos mil seis.

\section{Los temas de inconformidad planteados por los demandantes}

Los puntos de inconformidad expresados por los ciudadanos José Daniel Lizárraga Méndez y

El texto íntegro puede leerse en: www.te.gob.mx/documentacion/publicaciones/Serie_comentarios/14_SUP. JDC-10-2007.pdf 
Delia Angélica Ortiz Trujillo ante por la Sala Superior del Tribunal Electoral del Poder Judicial de la Federación fueron, en forma sintética, los siguientes:

a) Que el Instituto Federal Electoral estaría obligado a acatar la Ley Federal de Transparencia y Acceso a la Información Pública Gubernamental, en los términos indicados en su propio Reglamento.

b) Que la negativa a darle acceso a las boletas electorales del proceso de dos mil seis, afectaría sus derechos políticos, pues el resultado de la elección presidencial les generaba dudas sobre el manejo de su voto, por lo cual se debía permitirles contabilizar las boletas de todas las casillas instaladas en los trescientos distritos electorales de la República.

c) Que por su calidad de ciudadano que pagaba impuestos, le asistiría el derecho a que el Instituto Federal Electoral, le rindiera cuentas sobre su actuación, por lo que debía concedérsele la información que requería.

d) Que, en su calidad de reportero, intentaba desarrollar una investigación periodística sobre la elección presidencial del pasado dos de julio y, para ese fin, le resultaba indispensable acceder a las boletas utilizadas durante esa jornada electoral.

e) Que para que la prensa cumpla su función social, sería necesario que se les proporcionara la información, en este caso, de naturaleza electoral, bajo la custodia del Instituto Federal Electoral, pues los medios de comunicación eran los más importantes divulgadores de la información en manos del gobierno.

f) Que no asistía razón a los argumentos esgrimidos por la Comisión de Transparencia del Instituto Federal Electoral, al rechazarles su solicitud de información, aduciendo cuestiones relacionadas con la seguridad nacional, riesgo para la gobernabilidad, la legitimidad de las elecciones y la certeza en los resultados; pues desde la perspectiva periodística, era imposible que un medio de comunicación revierta el resultado de las elecciones realizadas el dos de julio de dos mil seis.

g) Que el proceso electoral federal ya había concluido y, por tanto, la información electoral debería ser pública, y permitírseles el acceso a las boletas electorales.

\section{La naturaleza de las boletas electorales según la Sala Superior del Tribunal Electoral}

Consideramos fundamental abordar la naturaleza jurídica de las boletas electorales y, si ellas, son formalmente antes y después de la jornada comicial un "documento público", como así lo señalara la Sala Superior del Tribunal Electoral del Poder Judicial en su Sentencia, o bien, se trata de sólo un documento que refleja una información sin aquella peculiaridad de "público". Se transcribe la parte pertinente de dicha Sentencia:

"Las boletas electorales son formalmente antes y después de la jornada comicial una documentación pública, creada para un fin eminentemente público y a costo del erario y materialmente, son una documentación pública, en tanto que son el recipiente del voto que en ellas se asienta por los sufragantes, empero, ni antes ni después de la jornada comicial, dichos documentos públicos pertenecen al dominio público, en tanto, se habrán de observar las medidas cautelares que la ley establece seguir a las autoridades que organizan las elecciones, para garantizar su confiabilidad previa, durante y posterior a la jornada electoral hasta en tanto, la expresión numérica de las boletas escrutadas sean asentadas en las actas en las que se deberán consignar los resultados de la elección en cada casilla instalada. Por 
ende, las boletas electorales son una documentación básica, prevista en la ley de la materia para una función determinada que encuentra en la jornada electoral su máxima justificación, hasta que los resultados de la votación sean radicados en las actas, a partir de entonces las actas se convierten en la referencia perdurable de la expresión de la voluntad popular de la elección. Reconocida la naturaleza jurídica de las boletas electorales como instrumentos continentes de información, debe esclarecerse si el acceso físico a ellas, está sujeto a alguna restricción o reserva que impida su publicidad."2

\section{i. ¿Las boletas electorales son documentos públicos?}

En la Sentencia de fecha 25 de abril de 2007 (SUP-JDC-10/2007 y SUP-JDC-88/2007 Acumulados) dictada por la Sala Superior del Tribunal Electoral se señala, expresamente, que las boletas electorales son "documentos públicos continentes de información":

“(...) el medio impreso por las cuales los electores manifiestan su preferencia electoral y por ello se adecúan a la definición de documentos públicos continentes de información." 3

Pero ¿para las leyes mexicanas son las boletas electorales documentos públicos o, más bien, es una apreciación extrema por parte de la Sala Superior del Tribunal Electoral? Tema que debe ser disipado habida cuenta la trascendencia de una u otra conclusión; esto es, si la Sala Superior del Tribunal Electoral tenía atribuciones suficientes como conceptuar o determinar cuál era la naturaleza jurídica de la "boleta electoral" o si sólo tenía atribuciones para declarar o enunciar si ella se adecuaba o no al concepto de "documento público".

Como quiera que la Sala Superior del Tribunal Electoral, al igual que todas las instituciones pertenecientes al ámbito del Estado, está supeditada al Derecho Público y a los Principios del Derecho Administrativo y sujeta, por cierto, a las atribuciones y facultades que expresamente le señale la legislación funcional, obviamente ésta se subordina a la Ley Federal de Transparencia y Acceso a la Información Pública y al Código Federal de Instituciones y Procedimientos Electorales, donde se prescribe diversas normas que son aplicables al presente caso. De ahí que resulta ser trascendental estar al tanto si existe alguna disposición en dichos cuerpos normativos u otros donde señale, defina o aclare lo que debe entenderse por "boletas electorales" y por "documento público".

Así, en el "Glosario del Código Electoral del Estado de México" elaborado por el Instituto Electoral del Estado de México se define a las "boletas electorales" del siguiente modo:

"Papeleta electoral por medio de la cual, durante la jornada electoral, los ciudadanos manifiestan su preferencia por un candidato o partido político en la elección de que trate, el formato es aprobado por el Consejo General del Instituto Electoral del Estado de México."

Aun cuando no hemos advertido que dicho Glosario haya sido aprobado mediante alguna norma de jerarquía similar a una Ley, podemos tomar en consideración que a las "boletas electorales" se las define como una "papeleta electoral" donde "los ciudadanos manifiestan su preferencia por un candidato o partido político" sin determinarse que sean "documentos públicos" y, menos, que reúnan tal naturaleza jurídica.

Igualmente, de la revisión efectuada a otros compendios legislativos mexicanos, tampoco hemos encontrado articulado legal alguno que estipule que las boletas electorales sean "documentos públicos".

2 Sentencia de fecha 25 de abril de 2007 (SUP-JDC-10/2007 y SUP-JDC-88/2007) dictada por la Sala Superior del

Tribunal Electoral del Poder Judicial de la Federación, pág. 107

3 Ídem, pág. 145 
No existiendo, entonces, norma legal alguna que declare que las boletas electorales sean "documentos públicos" es necesario, en primer lugar, determinar si ellas reúnen los condiciones para ser considerados como tales y, en segundo lugar, si la Sala Superior del Tribunal Electoral tenía atribuciones para determinar cuál era la naturaleza jurídica y qué debía entenderse por "boleta electoral" o si sólo tenía atribuciones para determinar si tal o cual documento se adecuaba o, más precisamente, reunía los requisitos para ser considerado "público", conforme a los principios contenidos en el Derecho Público.

En este orden de ideas, el artículo $129^{\circ}$ del Código Federal de Procedimientos Civiles (México) señala explícitamente qué debe entenderse por "documento público":

"Son documentos públicos aquellos cuya formación está encomendada por la ley, dentro de los límites de su competencia, a un funcionario público revestido de la fe pública, y los expedidos por funcionarios públicos, en el ejercicio de sus funciones. La calidad de públicos se demuestra por la existencia regular, sobre los documentos, de los sellos, firmas u otros signos exteriores que, en su caso, prevengan las leyes."

Del texto de ese articulado se puede reparar que, para que un "documento" pueda ser considerado "público", debe ser un título expedido o autorizado por funcionario público competente y con las solemnidades requeridas por la ley; aun cuando no especifica cuáles son estos documentos. El criterio del Código Federal de Procedimientos Civiles es que, para que se reconozca como "público", el documento debe reunir aquellas dos características. Pauta seguida por otras legislaciones, como son la española y la peruana.

En el caso de la legislación española, su Código Civil define al documento público en el artículo $1216^{\circ}$, cuando expresa que son "documentos públicos aquellos que han sido autorizados por un Notario o por un empleado público competente, con las solemnidades requeridas por la Ley", comprendiéndose a los siguientes:

a) Las escrituras públicas otorgadas con arreglo a Derecho.

b) Las certificaciones expedidas por Agentes de Bolsa y Corredores de Comercio con referencia al libro registro de sus respectivas operaciones y con las solemnidades que prescribe el art. 64 del Código de Comercio y Leyes Especiales.

c) Los documentos expedidos por los funcionarios públicos que estén autorizados para ello, en lo que se refiere al ejercicio de sus funciones.

d) Los libros de actas, estatutos, ordenanzas, registros, catastros y demás documentos que se hallen en archivos públicos o dependencias del Estado, Provincia o de los Pueblos, y las copias sacadas y autorizadas por los Secretarios y Archiveros por mandato de la autoridad competente.

e) Las Ordenanzas, estatutos y reglamentos de sociedades, comunidades o asociaciones, siempre que estuvieran aprobadas por autoridad pública y las copias autorizadas en la forma prevenida en el número anterior.

f) Las partidas o certificaciones de nacimiento, matrimonio y defunción dadas con arreglo a los libros por los párrocos o por los que tengan a su cargo el Registro Civil.

g) Las ejecutorias y las actuaciones judiciales de toda especie. 
Del mismo modo, tratándose de la legislación peruana, el artículo $235^{\circ}$ del Código Procesal Civil señala qué debe entenderse por documento público:

a) Aquellos otorgados por funcionario público en ejercicio de sus atribuciones; y

b) Las escrituras públicas y demás documentos otorgados ante o por notario público, según la ley de la materia.

Como se puede reparar de las lecturas de los textos, las nociones son muy próximas entre sí; destacándose que un "documento público" es tal sólo cuando reúne los dos siguientes requisitos esenciales: (1) si es emitido por funcionario o notario público; y, (2) si reúne los requisitos de ley. La ley -sea peruana, española o mexicana- no posibilita otra forma para establecer los requisitos esenciales para entender qué es un "documento público"; de ahí que la autoridad competente se encuentra limitada sólo a valorar si un determinado documento reúne las exigencias fundamentales para ser considerado "público". Aquél que no contenga estas características no puede ser considerado "público", precisándose que la legalización o certificación de un documento privado por parte del funcionario o notario no lo convierte en ello.

Pero, ¿acaso las "boletas electorales" reúnen los requisitos esenciales que hemos indicado anteriormente? La respuesta parece ser definitivamente no, pues las "boletas electorales" no están suscritas por funcionario público alguno y, por lo tanto, no podrían tener la característica de ser documento "público".

En efecto, aun cuando el diseño o modelo de las "boletas electorales" es aprobado por la autoridad electoral pertinente ${ }^{4}$, ellas no son suscritas -al momento de iniciarse el proceso electoral y constituirse la respectiva mesa directiva electoral- por funcionario público alguno. Recordemos que las "boletas electorales" son documentos que contienen una expresión política manifestada por un ciudadano y que está previamente suscritas por tres ciudadanos investidos de ciertos poderes otorgados por Ley; pero que no son funcionarios públicos, en las proporciones o dimensiones establecidas en las leyes mexicanas.

Conforme al artículo $108^{\circ}$ de la Constitución Política de los Estados Unidos Mexicanos, se reputa como servidores públicos a los representantes de elección popular, a los miembros del Poder Judicial Federal y del Poder Judicial del Distrito Federal, los funcionarios y empleados y, en general, a toda persona que desempeñe un empleo, cargo o comisión de cualquier naturaleza en el Congreso de la Unión, en la Asamblea Legislativa del Distrito Federal o en la Administración Pública Federal o en el Distrito Federal, así como a los servidores públicos de los organismos a los que la Constitución otorgue autonomía.

Por su parte, el inciso 1) del Artículo $154^{\circ}$ Código Federal de Instituciones y Procedimientos Electorales (México) ${ }^{5}$ establece que las mesas directivas de las casillas electorales estarán conformadas por ciudadanos, facultados para recibir la votación y realizar el escrutinio y cómputo en cada una de las secciones electorales, como así lo señala explícitamente. En ningún extremo de la ley mexicana se estipula que serán funcionarios o servidores públicos los que integrarán las

4 El Consejo General del Instituto Federal Electoral, conforme al Inciso II) del artículo $118^{\circ}$ del Código Federal de Instituciones y Procedimientos Electorales, es la instancia del Estado encargada de aprobar, entre otros, el modelo de las boletas electorales, de las actas de la jornada electoral y los formatos de la demás documentación electoral.

5 El inciso 1) del Artículo $154^{\circ}$ Código Federal de Instituciones y Procedimientos Electorales establece que las mesas directivas son conformadas por ciudadanos que no revisten potestades de funcionarios públicos (" 1 . Las mesas directivas de casilla por mandato constitucional, son los órganos electorales formados por ciudadanos, facultados para recibir la votación y realizar el escrutinio y cómputo en cada una de las secciones electorales en que se dividan los 300 distritos electorales.") 
mesas directivas o de sufragio. Igual criterio es seguido en otras legislaciones, como es el caso de la ley peruana 6 .

Ahora bien, si las "boletas electorales" no son documentos que reúnen los requisitos de ley para ser considerados como tales y no existía norma expresa que determinara que las "boletas electorales" eran "documentos públicos", la consecuente reflexión que debiera realizarnos es si las instituciones o entidades de la Administración Pública, sea mexicana, española o peruana, y en especial la indicada Sala Superior del Tribunal Electoral de la Federación (México), tenía capacidad jurídica para conceptuarlas al momento de expedirse la Sentencia bajo nuestro examen.

\section{ii. ¿La Administración Pública tenía capacidad jurídica para definir que las "boletas electorales" eran "documentos públicos"?}

Al respecto, es importante señalar que no hemos encontrado articulado alguno en la Ley Orgánica del Poder Judicial de la Federación ni en su Reglamento Interno u otras como para concluir categóricamente que el Tribunal Electoral del Poder Judicial de la Federación ${ }^{(7)}{ }^{(8)}$ se encontraba habilitada con poderes o facultades suficientes para señalar o tipificar qué documentos eran públicos o no, así como fue establecido aquella instancia en su Sentencia. Es decir, nuestro reparo apunta a determinar si la Sala Superior del Tribunal Electoral del Poder Judicial de la Federación tenía atribuciones suficientes, entre otras, para fijar requisitos a algún documento para que sea considerado "público" o, si sólo tenía atribuciones para precisar si tal o cual documento reunía o no las características de Ley para ser considerado como "público". Una distinción que, por cierto, es hartamente polémica pero necesaria para conocer sobre las consecuencias de la eficacia del fallo de la Sala.

Es importante recordar que el Derecho Público, al cual están sometida todas las instituciones y entidades de la Administración Pública al igual que la Sala Superior del Tribunal Electoral, regula las relaciones entre las personas y entidades privadas con los órganos que ostentan el poder político cuando estos últimos actúan en ejercicio de sus legítimas atribuciones y potestades públicas y de acuerdo con el procedimiento legalmente establecido.

A decir de la doctrina jurídica, el Derecho Público es la parte del ordenamiento jurídico que regula las relaciones entre las personas y entidades privadas con los órganos que ostentan el poder público cuando estos últimos actúan en ejercicio de sus legítimas potestades públicas y según el procedimiento legalmente establecido, y de los órganos de la Administración Pública entre sí, así como las relaciones de orden, subordinación y coordinación de los órganos y divisiones funcionales del Estado entre sí.

Lo distintivo del Derecho público, como así lo establece la doctrina, es que sus mandatos no se encuentran sujetos a la autonomía de la voluntad que pudiesen ejercer las partes; esto es, que sus atribuciones no pueden ser modificadas por las partes en uso legítimo de su autonomía de la voluntad, como ocurre en el Derecho Privado.

La autonomía de la voluntad, según Kant, se encuentra referida a la capacidad del individuo para dictarse sus propias normas morales. El concepto constituye actualmente un principio básico

6 La Ley Orgánica de Elecciones del Perú (aprobada por Ley N²6859) señala lo siguiente: “Artículo $51^{\circ}$. - Las mesas de sufragio tienen por finalidad recibir los votos que emitan los electores en los procesos electorales de referéndum y otras consultas populares; así como el escrutinio, el cómputo y la elaboración de las actas electorales ". "Artículo $\mathbf{5 2}$. - En cada distrito político de la República se conforman tantas mesas de sufragio como grupos de 200 (doscientos) ciudadanos hábiles para votar como mínimo y 300 (trescientos) como máximo existan. El número de ciudadanos por mesa de sufragio es determinado por la Oficina Nacional de Procesos Electorales."

7 El Artículo $209^{\circ}$ de la Ley Orgánica del Poder Judicial de la Federación establece taxativamente las atribuciones de la Comisión de Administración.

8 Por su parte el Artículo $31^{\circ}$ del Reglamento Interno del Tribunal Electoral del Poder Judicial de la Federación señala las atribuciones de la Comisión de Administración. 
en el Derecho Privado, que parte de la necesidad que el ordenamiento jurídico capacite a los individuos para establecer relaciones jurídicas acorde a su libre voluntad; es decir, son los mismos individuos los que dictan sus propias normas para regular sus relaciones privadas. Mientras que las atribuciones y potestades de las instituciones y entidades de la Administración Pública son mandatos irrenunciables y obligatorios. La justificación de ello es que regulan derechos que hacen al orden público y deben ser acatados por toda la ciudadanía e, incluso, por las autoridades que gobiernan las entidades públicas a instancias de su subordinación al mismo Estado.

Siendo ello así, y al no existir disposición legal que autorice expresamente a la Sala Superior del Tribunal Electoral para establecer requisitos o atribuir características de "público" a la "boleta electoral" o cualquier otro documento, a nuestro juicio esta Instancia asignó la naturaleza de "público" a un documento que no recogía las particularidades señaladas por el artículo $129^{\circ}$ del Código Federal de Procedimientos Civiles. Claro está que dicha entidad sí tenía facultades para evaluar si tal o cual documento cumplía o no con los requisitos señalados por Ley para ser considerado "público", pero no -reiteramos- para fijar las características o requisitos para que tal o cual documento sea "público" o no.

Ahora bien, si la Sala Superior del Tribunal Electoral no tenía esa específica atribución ¿cuál sería la consecuencia jurídica del fallo? Obviamente carecería de la validez requerida por contar vicios en las potestades funcionales.

\section{iii. ¿Queé información contiene las boletas electorales?}

Si las "boletas electorales" no reúnen, a nuestro juicio, características de "documentos públicos", la incógnita se subordinaría -entonces- a puntualizar cuál es la naturaleza jurídica de este documento.

Siguiendo la misma exégesis, debiéramos referirnos al Código Federal de Procedimientos Civiles (México) cuyo artículo $133^{\circ}$ establece expresamente lo siguiente:

"Son documentos privados los que no reúnen las condiciones previstas por el artículo 129."

La consecuencia de lo preceptuado en dicho articulado es que, aquel documento que no reúne las características de "público", debe ser considerado -entonces- un documento "privado". Ni la legislación ni la doctrina admiten otra posibilidad. De ahí que las "boletas electorales", estando bajo resguardo del Estado, aun luego de concluido el proceso electoral, debieran ser calificados -a nuestro juicio- como "documentos privados que se encuentran en poder o custodia por parte del Estado".

Siendo las "boletas electorales" documentos privados supeditadas a estas particularidades, la siguiente cuestión sería determinar si éstas se encuentran sujetas al Principio de Publicidad que se contiene en la Ley Federal de Transparencia y Acceso a Información Pública, así como a las presunciones y obligaciones que se establece en las leyes; esto es, a la presunción de ser un bien público, a la obligación de su entrega y a la promoción de la gestión y medidas de transparencia.

Un aspecto interesante de la Sentencia bajo comentario es que señala que las "boletas electorales" tenían la peculiaridad de ser "instrumentos continentes de información". De manera que la siguiente interrogante que debiéramos plantearnos es si aquellas "boletas electorales" eran efectivamente instrumentos con contenido de información, como así lo señalara la Sala Superior del Tribunal Electoral, y si ella era de carácter "público".

Si la "información pública" constituye aquellos datos, fuentes e ideas que se encuentran en elámbito de las entidades del Estado, pudiendo ser escritos e impresos, fotografías, grabaciones o soporte 
digital, coincidimos plenamente con la Sala Superior del Tribunal Electoral que son, efectivamente, "instrumentos continentes de información" aun cuando no sean "documentos públicos". Esto quiere decir que el Estado puede tener en su poder "documentos públicos" y "documentos privados" no obstante estar sujetos a diversas reglas en su entrega a los solicitantes o peticionarios.

En efecto, de la lectura del texto de la Ley Federal de Transparencia y Acceso a Información Pública se puede advertir que no todo documento en poder del Estado o de sus instituciones puede ser considerado "documentos públicos" sino "bienes públicos"; de ahí que la naturaleza es distinta en un caso u otro y el sometimiento a la publicidad disímiles. En virtud de lo señalado, entonces, se puede concluir preliminarmente que las "boletas electorales" son documentos privados en poder del Estado que encierran información con contenido, opción u opinión política de ciudadanos.

Por cierto, que nos hemos venido refiriendo a las "boletas electorales" que tienen un contenido informativo, es decir que se haya expresado una opción política determinada, como es el caso de las "boletas electorales" con sufragio; pero, ¿qué del caso de aquellas que no contienen sufragio alguno?; o sea que el ciudadano no se presentó a los comicios ni votó.

De seguirse la elucidación de la propia Sala Superior del Tribunal Electoral se tendría que afirmar que es posible la existencia de "boletas electorales" sin contenido informativo; pues aquel ciudadano que no ha sufragado no habría manifestado su preferencia por un candidato o partido político determinado y permanecerían algunas boletas suscritas por los integrantes de las mesas electorales sin ser votadas. Es decir, continuando con aquel criterio, es posible señalar la existencia de "boletas electorales", que, suscritas por los integrantes de la mesa directiva, no contengan sufragio y, por consiguiente, no posean información alguna. En tal caso, es admisible destacar que existirían dos grupos de "boletas electorales": (a) aquellas con sufragio y con contenido informativo; $y$, (b) aquellas sin sufragio $y$, por lo tanto, sin contenido informativo; aspectos que abordaremos más adelante.

\section{LAS BOLETAS ELECTORALES: ¿SUJETAS AL PRINCIPIO DE PUBLICIDAD?}

Si bien hemos afirmado que las "boletas electorales", estando bajo resguardo del Estado, son "documentos privados que se encuentran en poder o custodia por parte del Estado y que contienen información de los ciudadanos donde expresan opción u opinión política determinada", el siguiente asunto de reflexión es determinar si aquellas se encuentran igualmente sometidas al Principio de Publicidad que rigen a los bienes públicos o no.

Para ello es importante recordar algunos preceptos que rigen a la libertad de información; esto es que es un derecho natural y fundamental para el ser humano e, incluso, puede decirse que es inviolable; pero que no es un derecho absoluto.

La libertad de información está sujeta a restricciones cuando choca con otros derechos que suponen una mayor protección, como así lo establecen el Pacto Internacional de Derechos Civiles y Políticos y la Convención Americana sobre Derechos Humanos. El inciso 3) del artículo $19^{\circ}$ del Pacto Internacional de Derechos Civiles y Políticos señala lo siguiente:

"El ejercicio del derecho (de información) entraña deberes y responsabilidades especiales. Por consiguiente, puede estar sujeto a ciertas restricciones que deberán, sin embargo, estar expresamente fijadas por ley y ser necesarias para: a. Asegurar el respeto a los derechos o la reputación de los demás; b. La protección de la seguridad nacional, el orden público o la salud o moral públicas".

(El agregado entre paréntesis es nuestro) 
Mientras que, en forma similar, el inciso 2) del artículo $13^{\circ}$ de la Convención Americana sobre Derechos Humanos prescribe:

"El ejercicio del derecho (de información) no puede estar sujeto a previa censura sino a responsabilidades ulteriores, las que deberán estar expresamente fijadas por la ley y ser necesarias para asegurar: a. El respeto a los derechos o a la reputación de los demás, o b. La protección de la seguridad nacional, el orden público o la salud o la moral públicas".

(El agregado entre paréntesis es nuestro)

Igualmente, los autores consultados, entre ellos López Ayllón, Perla Anaya y Buitrago López9 coinciden -enfáticamente- en señalar que existen limitaciones del derecho a la información. Concuerda en ello el Prof. Miguel Julio Rodríguez Villafañe ${ }^{10}$ quien ha sostenido que:

"(...) si bien el derecho a la información ocupa un lugar de privilegio en los derechos esenciales a cuidar, el mismo no es absoluto, puesto que no puede extenderse en detrimento de la necesaria armonía que debe guardar con los restantes derechos constitucionales que se han consagrado y que también debe garantizarse. El especial reconocimiento constitucional de que goza esta libertad de buscar, dar recibir y difundir información e ideas de toda índole, no implica que ello deba realizarse de manera irresponsable que anule o contradiga otros derechos humanos también garantizados por el sistema. Pues, no es admisible sostener que entre los valores que enuncia la Constitución (de Argentina) ${ }^{11}$ exista una jerarquía que conduzca a reconocerle prioridad a alguno de ellos en detrimento o anulación de otros. Aunque en su dinámica el derecho a la información tenga seguridades especiales, como la imposibilidad de la censura previa".

De la lectura de los citados textos del Pacto Internacional de Derechos Civiles y Políticos y de la Convención Americana sobre Derechos Humanos se puede colegir, en primer lugar, que unos derechos humanos son más importantes que otros.

Si la información afecta, por ejemplo, la reputación o la intimidad de otros o la seguridad nacional, implica que estos derechos son más próximos al individuo o son indispensables para la convivencia en paz y están inexcusablemente más protegidos por la comunidad. Los derechos humanos que se hayan vinculados a la propia existencia del individuo o que son necesarios para el orden público y que son consubstanciales e irrenunciables por ser fundamentales para el desarrollo del individuo o para la convivencia en sociedad, son más protegidos que otros.

De esta manera, la diferencia existente entre unos derechos humanos que son más protegidos que otros radica en que unos son inalienables y otros pueden ser renunciables. De ahí que, y en ese orden, el primer derecho inalienable de la persona sea el derecho a la vida y de este reconocimiento, por supuesto, se derivan los demás derechos humanos.

Pero la comprobación de este derecho inalienable y fundamental no sólo es tener derecho a existir, sino además a que esta existencia sea noble. Entonces de ello parten aquellos derechos como a vivir en libertad, a tener intimidad y a tener dignidad y honor, que se imponen de manera total sobre otros derechos. Así que el derecho a tener una vida digna prima, por ejemplo, sobre el derecho a difundir una información, puesto que los derechos a vivir en libertad, a tener intimidad y a tener honor están íntimamente relacionados con la existencia misma y al "crecimiento interior" (Desantes 1990: 23) ${ }^{12}$.

\footnotetext{
9 Véase López Ayllón, Perla Anaya y Buitrago López (1998).

${ }^{10}$ Véase Rodríguez Villafañe (2002: 45)

${ }^{11} \mathrm{El}$ agregado entre paréntesis es nuestro.

12 Véase Desantes (1990: 23).
} 
Por tanto, el Principio de la Publicidad de una información cede ante otro derecho natural como el derecho al honor o el derecho a la buena imagen o la reputación de las personas. El sujeto activo de la información, entonces, debe valorar si prevalece el derecho a proporcionar la información a otro derecho natural concurrente que necesita ser más respetado.

De aceptarse, por lo tanto, que alguien tiene el privilegio de proporcionar información para dañar el honor o la intimidad de otra persona, sería negar que todos los individuos tengan el mismo derecho de protección e impondría a algunos una facultad superior que una concepción humanista de la información rechaza. Ésta revela que la información "es misión del hombre para el hombre, es decir nace y termina en la persona humana, de manera tal que si, por alguna razón, la información atentara contra la persona, contradeciría su propio ser, la razón de su existencia y su finalidad ontológica. Sucede (...) cuando invade la intimidad de las personas, cuando atenta contra la dignidad u honor de ellas, cuando daña su imagen o cuando lesiona su derecho a la verdad y a toda la verdad. Este derecho de los individuos y de la sociedad es consubstancial al derecho a la información" (Osorio Meléndez 1997: 87) ${ }^{13}$.

Todo esto quiere decir que con el derecho de la información no se crean privilegios para algunas personas en detrimento de otros. Todos los hombres son iguales en dignidad y, por lo tanto, están protegidos en libertad individual y frente a las pretensiones de los demás.

Aun cuando la individualidad de las personas es tan importante como su entorno social y cuando la difusión de una información afecta el bien común es imprescindible que el sujeto activo guarde silencio o se la reserve. Si el hombre persigue aquellas condiciones necesarias para lograr su total desarrollo humano y el bienestar de la sociedad, no es admisible entonces que el derecho particular a difundir una información se privilegie sobre el bien común. Por tanto, un derecho que colisiona con el bienestar social y con el bien común no puede estar protegido por ningún cuerpo normativo ni tener amparo de los tratados internacionales sobre derechos humanos.

Tal como lo mencionáramos en líneas anteriores, la sociedad tiene derecho a exigir de los ciudadanos todo lo que sea necesario para el bien común; y, el uso de los derechos humanos sólo puede limitarse cuando afecten el bien común: "todos los hombres y grupos sociales, en el ejercicio de sus derechos están obligados por la ley moral a tener en cuenta los derechos ajenos y sus deberes para con los demás y para con el bien común de todos. Hay que obrar con todos conforme a la justicia y al respeto debido del hombre"14.

El bien común, nos explican María Teresa Herrán y Javier Darío Restrepo, no es la suma de bienes particulares, pues -por ejemplo- la paz "(...) no es la suma de unos bienes individuales, sino un valor realizado en y por cada uno de los miembros de una comunidad. Por eso, el bien común ha sido definido como un bien superior a cada uno. El bien común es siempre el principio supremo del que no se puede prescindir. Lo que distingue a una sociedad humana de una masa deshumanizada es la conciencia de ese bien común que ejerce una función aglutinante y de ideal compartido por todos. Desde el punto de vista ético-social, una sociedad adquiere forma cuando sus miembros asumen como propio el deber de trabajar por ese bien común. A mayor conciencia de ese deber y de ese ideal, mayor cohesión y vigor de la sociedad. Por el contrario, las crisis de la sociedad -sea la familiar o la nacional- se hallan estrechamente relacionadas con la defectuosa o vacilante conciencia alrededor del bien común. El bien común es, pues, el ideal que mantiene unida y activa a una comunidad" (Herrán y Restrepo 1998: 146)

\footnotetext{
${ }^{13}$ Véase Osorio Meléndez (1997: 87)

${ }^{14}$ Dignitatis Humanae, 7; Gaudium et Spes, 71, 75. Véase Osorio Meléndez.

${ }^{15}$ Véase Herrán y Restrepo (1998: 146).
} 
Pero, obviamente, las relaciones entre los intereses individuales y el bien común no son siempre amistosos y coincidentes; y, con cierta frecuencia están sujetas a conflictos. En esos casos debe prevalecer el bienestar común frente al bienestar particular, pues el bien común es la prosperidad de la sociedad y la plenitud de la existencia de todos los hombres y porque el desarrollo de la colectividad compensa a los individuos en su entrega por subordinarse al bien común, como lo entendía San Agustín ${ }^{16}$.

Por cierto, que los derechos a la vida, al honor, a la identidad, a la expresión, a la información, entre otros tantos, pertenecen al ámbito de los derechos particulares, pero ellos también tienen su soporte en el bien común. Así, si se privilegia el derecho a proporcionar una información es porque prima el derecho de la sociedad a estar adecuada y libremente informada y porque de esta manera lo exige el cuerpo normativo para lograr el bien común.

Dicho esto, es comprensible que las Constituciones Políticas, tanto del caso de México ${ }^{17}$ como del caso del Perú18, así como sus respectivas leyes de transparencia y acceso a información pública coincidan que la entrega de información pública por parte del Estado está sujeta las limitaciones de las comunicaciones y documentos privados, de los archivos privados y públicos sobre datos personales y de los archivos secretos que comprometan la seguridad nacional o de las personas $\left({ }^{19}\right)\left({ }^{20}\right)$.

Ahora bien, si con la entrega de la información es posible determinar la ideología u opinión política del ciudadano expresado en la "boleta electoral", coincidimos con aquel criterio que, con limitar tal entrega, se estaría protegiendo un derecho mayor que el revelarlo: la opción política del ciudadano y el secreto de los datos personales. De ahí que, sólo bajo la posibilidad que sea identificable o reconocible la persona cuya información se solicita, se violaría, sin lugar a dudas, la reserva e intimidad que hemos señalado, advirtiendo que las consecuencias jurídicas de la entrega o no de las copias de las "boletas electorales" son muy controvertibles.

\section{Las boletas electorales con sufragio}

Si el artículo $3^{\circ}$ Ley Federal de Transparencia y Acceso a la Información Pública Gubernamental (México) estipula que, para los efectos de la Ley, se entenderá por datos personales a "la información concerniente a una persona física, identificada o identificable, entre otra, la relativa a su origen étnico o racial, o que esté referida a las características físicas, morales o emocionales, a su vida afectiva y familiar, domicilio, número telefónico, patrimonio, ideología y opiniones políticas, creencias o convicciones religiosas o filosóficas, los estados de salud físicos o mentales, las preferencias sexuales, u otras análogas que afecten su intimidad" y el artículo $4^{\circ}$ de la misma Ley señala que es su objetivo, entre otros, "garantizar la protección de los datos personales en posesión de los sujetos obligados", evidentemente el propósito del texto es proveer todos aquellos elementos normativos que resguarden el derecho a la intimidad de la persona.

Obsérvese que el texto señala que la información será resguardada en tanto la persona física pueda ser "identificada" o bien "identificable"; es decir, que basta el reconocimiento de la identidad de la persona mediante la deducción o la presunción para que sea sujeto del derecho a la intimidad y, por tanto, la reserva en la entrega de información a terceros.

${ }^{16}$ Véase Osorio Meléndez.

${ }^{17}$ Artículo $6^{\circ}$ de la Constitución Política de los Estados Unidos Mexicanos.

${ }^{18}$ Incisos 5), 6) y 10) del Artículo $2^{\circ}$ de la Constitución Política del Perú

${ }^{19}$ Ver textos de los artículos $15^{\circ}, 15-\mathrm{A}, 15-\mathrm{B}$ y $15-\mathrm{C}$ de Ley de Transparencia y Acceso a la Información Pública (Ley N ${ }^{\circ}$ 27927) del Perú.

${ }^{20}$ Ver texto de los artículos $13^{\circ}$ y $14^{\circ}$ de la Ley Federal de Transparencia y Acceso a la Información Pública Gubernamental de México. 
La Ley Federal de Transparencia y Acceso a la Información Pública Gubernamental dispone que, con la sola eventualidad que sea "identificable" la persona física, debiera protegerse el derecho a la intimidad sin que sea necesario el inmediato reconocimiento de la identidad para que sea amparada por la Ley.

En tal caso, la entidad a cargo del resguardo, no podría hacer entrega de información, salvo que haya anuencia de los propios individuos, como reza el Artículo $21^{\circ}$ de la Ley:

"Los sujetos obligados no podrán difundir, distribuir o comercializar los datos personales contenidos en los sistemas de información, desarrollados en el ejercicio de sus funciones, salvo que haya mediado el consentimiento expreso, por escrito o por un medio de autenticación similar, de los individuos a que haga referencia la información."

Ahora bien, si hemos afirmado que la Ley se refiere a la sola probabilidad de ser reconocible la identidad de la persona física ¿es hipotéticamente posible que se pueda identificar el voto y, por ello, la opción política expresada por los ciudadanos en la boleta electoral? Creemos que la respuesta debe ser afirmativa.

Imaginémonos la siguiente probabilidad: que todos los electores de una mesa de sufragio hubiesen optado por un mismo candidato. De proporcionarse esa información sería probable, aun remotamente, que el solicitante pudiese desentrañar la opción política que tuvo cada uno de los electores de aquella mesa de sufragio. Pero, claro, advertimos que esa eventualidad es remota pero no imposible jurídicamente; y, como tal, sujeta a regulación general por parte de la Ley y su aplicación a las situaciones jurídicas existentes.

En consecuencia, de entregarse copias de las "boletas electorales" a cualquier persona que lo solicite, se podría violar -a nuestro criterio- la reserva de la información que la propia Ley Federal de Transparencia y Acceso a la Información Pública Gubernamental protege. La simple probabilidad de la violación de la intimidad del elector es suficiente para exceptuarla de la entrega de la información solicitada.

Distinto es el caso de las actas de escrutinio que, por inferencia del Inciso b) del Artículo $247^{\circ}$ del Código Federal de Instituciones y Procedimientos Electorales, debe entenderse que son de carácter público, aun cuando pudiese dar la misma hipótesis a que no hemos referido líneas arriba:

"Los representantes de los partidos políticos debidamente acreditados ante las mesas directivas de casilla tendrán los siguientes derechos: (...) b) Recibir copia legible de las actas de instalación, cierre de votación y final de escrutinio elaboradas en la casilla."

Igualmente, en razón de lo preceptuado en el Artículo $18^{\circ}$, in fine, del Código Federal, no se considera sujeto a confidencialidad la información que se halle en los registros públicos o en fuentes de acceso público, como es el presente caso.

\section{Las boletas electorales sin sufragio.}

Sí, al cierre de los comicios, es posible la existencia de "boletas electorales" sin sufragio, podemos afirmar que aquellas no encierran información política habida cuenta que ciertos ciudadanos no habrían ejercido opción alguna en el proceso electoral.

Así es, de continuarse con la exégesis de la misma Sala Superior del Tribunal Electoral, se tendría que aseverar la existencia de "boletas electorales" que podrían no contener información alguna y, por lo tanto, no sujetas al Principio de Publicidad. 
Si la Sala Superior del Tribunal Electoral ha manifestado que las "boletas electorales" que han sido sufragadas son "instrumentos continentes de información", se puede inferir o colegir "contario sensu" que aquellas que no han sido sufragadas no contienen información y, por consiguiente, no contienen dato alguno para proporcionar. De ahí que la cuestión se reduciría, entonces, a determinar si las instituciones o las entidades públicas se encuentran obligadas o intimadas a entregar documentos privados que no contengan información. La respuesta, a nuestro criterio, debiera ser negativa pues en ningún extremo de la Ley Federal de Transparencia y Acceso a la Información Pública Gubernamental admite esta eventualidad, aun cuando no se les prohíbe.

No obstante, hemos reparado que -en la comentada Sentencia- la Sala Superior del Tribunal Electoral del Poder Judicial de la Federación no se pronunció en modo alguno sobre este extremo, pese a que ello era -también- materia de solicitud de parte de los ciudadanos José Daniel Lizárraga Méndez y Delia Angélica Ortiz Trujillo.

En efecto, en el Numeral Cuarto de los Considerandos de la Sentencia, la misma Sala fija lo que sería materia de la litis, sosteniéndose -entre otros- en el propio pedido formulado por el ciudadano José Daniel Lizárraga Méndez:

“(...) Por mi propio derecho, en uso pleno de mis facultades mentales y en goce de mis garantías individuales, José Daniel Lizárraga Méndez, (...) acudo ante el Tribunal Electoral del Poder Judicial de la Federación para tramitar el presente juicio para la Protección de los Derechos Políticos Electorales del Ciudadano (...). Soy periodista de profesión y no abogado por lo que solicito respetuosamente a esta autoridad apoyo para que si, lo consideran pertinente, aplique la suplencia de la queja sobre los hechos que a continuación narraré (...). El pasado 8 de agosto del 2006, solicité al IFE acceso a los sobres con las boletas sobrantes, inutilizadas, los votos válidos y nulos de todas las casillas instaladas durante la jornada del pasado 2 de julio del 2006, en todo el país, para la elección de Presidente de la República (...)"21

(El subrayado es nuestro)

De la lectura del pedido se advierte que el demandante no sólo solicitó copias de las "boletas electorales" correspondientes a los votos válidos y nulos de todas las casillas instaladas durante la jornada comicial sino, además, de las boletas sobrantes e inutilizadas; es decir, la petición comprendía tanto copias de aquellas boletas que contenían sufragio como de aquellas otras que no lo contenían. Esto significa que la cuestión contenciosa abarcaba los extremos de boletas con y sin contenido informativo y, por consiguiente, obligaba a la Sala Superior a pronunciarse sobre todos los extremos de la litis.

La Sala fijó los puntos controvertidos con relación a los hechos afirmados en la solicitud del ciudadano José Daniel Lizárraga Méndez que fueron contradichos por la institución demandada y aquellos otros que no tuvieron pronunciamiento por parte de la Comisión del Consejo para la Transparencia y el Acceso a la Información del Instituto Federal Electoral; es decir, los puntos controvertidos correspondían a los hechos sobre los cuales existen discrepancias y sobre los que eran materia de la petición.

Evidentemente, esta omisión tampoco es menor pues las sentencias que causen fallo deben contener una relación de las cuestiones planteadas en la solicitud o pedido de los demandantes, así como las consideraciones jurídicas aplicables, tanto legales como doctrinarias, y resolver con

21 Sentencia de fecha 25 de abril de 2007 (SUP-JDC-10/2007 y SUP-JDC-88/2007) dictada por la Sala Superior del Tribunal Electoral del Poder Judicial de la Federación, pág. 25 
toda precisión los puntos de controversia, como lo establece en forma indubitable el Artículo $222^{\circ}$ del Código Federal de Procedimientos Civiles:

"Las sentencias contendrán, además de los requisitos comunes a toda resolución judicial, una relación sucinta de las cuestiones planteadas y de las pruebas rendidas, así como las consideraciones jurídicas aplicables, tanto legales como doctrinarias, comprendiendo, en ellas, los motivos para hacer o no condenación en costas, y terminaran resolviendo con toda precisión, los puntos sujetos a la consideración del tribunal, y fijando, en su caso, el plazo dentro del cual deben cumplirse".

(El subrayado es nuestro)

Si convenimos que la Sala Superior del Tribunal Electoral del Poder Judicial de la Federación omitió pronunciarse y fallar sobre aquél extremo del pedido del ciudadano José Daniel Lizárraga Méndez ¿cuál sería la consecuencia procesal de esa ausencia? Sin duda la nulidad de la resolución habida cuenta de su trascendencia y agravio producido en el pedido materia de nuestras observaciones.

Recordemos que la nulidad procesal es el estado de anormalidad o presencia defectuosa de requisitos que condicionan la existencia regular del acto procesal o de las resoluciones, originado en la carencia de alguno de sus elementos constitutivos o de vicios existentes en ellos, que lo coloca en la situación procesal de ser declarado inválido. Un acto procesal o una resolución que adolecen de una circunstancia fijada en las leyes procesales como necesaria para que el acto produzca sus efectos deberían ser considerados nulos.

Aun cuando la Sentencia dictada por la Sala Superior del Tribunal Electoral del Poder Judicial de la Federación contiene un excelente dictamen en materia del derecho a la información, consideramos que se ha omitido un pronunciamiento sobre uno de los extremos del pedido del ciudadano José Daniel Lizárraga Méndez que inducen, igualmente, a la invalidez del fallo.

\section{CONCLUSIONES}

La primera conclusión es que las "boletas electorales", estando bajo resguardo del Estado, aun luego de concluido el proceso electoral, debieran ser calificados como "documentos privados que se encuentran en poder o custodia por parte del Estado"; de manera que nos alejamos de la apreciación realizada por la Sala Superior del Tribunal Electoral que ha sostenido que ellas son "documentos públicos".

Una segunda conclusión es que, al no existir disposición legal que autorizara expresamente a la Sala Superior del Tribunal Electoral del Poder Judicial de la Federación para establecer requisitos o atribuir características de "público" a la "boleta electoral" o cualquier otro documento, esa Instancia habría asignado la naturaleza de "público" a un documento que no reunía las particularidades señaladas por el artículo $129^{\circ}$ del Código Federal de Procedimientos Civiles. Claro está que dicha entidad sí tenía facultades para evaluar si tal o cual documento cumplía o no con los requisitos señalados por Ley para ser considerado "público", pero no para fijar las características o requisitos para que tal o cual documento sea "público" o no. La consecuencia jurídica con un vicio, en ese extremo, es que induce al fallo a que carezca de la validez requerida.

La tercera conclusión radicaría en que, preliminarmente, se pueda sostener que las "boletas electorales" son documentos privados en poder del Estado que encierran información con contenido, opción u opinión política de ciudadanos si es que el ciudadano ha ejercido su elección o voto; pero es posible señalar la existencia de "boletas electorales", que, suscritas por los integrantes de la mesa directiva, no contengan sufragio y, por consiguiente, no posean información 
alguna. En tal caso, es admisible destacar que existirían "boletas electorales" con sufragio y con contenido informativo y, otras, sin sufragio y, por lo tanto, sin contenido informativo. En el primer caso, a nuestro criterio, no se encuentra sujeta al Principio de Publicidad sino a las reservas y excepciones que señala la Ley Federal de Transparencia y Acceso a la Información Pública Gubernamental; mientras que, en el segundo caso, no está sometida a las reglas de entrega que señala la misma Ley.

Una última conclusión se hallaría en que, aun cuando la Sentencia dictada por la Sala Superior del Tribunal Electoral del Poder Judicial contiene un excelente dictamen en materia del derecho a la información, se ha omitido un pronunciamiento sobre aquellas boletas no empleadas para el sufragio, a pesar que era uno de los pedidos del ciudadano José Daniel Lizárraga Méndez. Sin lugar a dudas, la Sentencia debió comprender ese extremo y su omisión conduce ineludiblemente a la invalidez del fallo.

\section{BIBLIOGRAFÍA}

- BUITRAGO LÓPEZ, Elker "La regulación legal y la autorregulación de los medios: organismos colegiados con participación ciudadana”. En Cámara de Diputados de México "El Derecho de la Información en el Marco de la Reforma del Estado en México", Tomo I, México DF, 1998.

- DESANTES, José María "Información y Derecho. La identidad del informador frente a la información". Colección "Actualidad e Información", Santiago 1990, Pág. 23 y ss. En Hugo Osorio Meléndez en "Políticas de Información y Derecho. Estudio Comparativo", Universidad Metropolitana de Ciencias de la Educación, Impresos Universitaria, Santiago de Chile 1997.

- HERRÁN, María Teresa y RESTREPO, Javier Darío "Ética para periodistas", 2da. edición aumentada, Editores Tercer Mundo, Santafé de Bogotá 1998.

- LÓPEZ AYLLÓN, Sergio "El derecho de la información como derecho fundamental".

- PERLA ANAYA, José "La libertad de información dentro del derecho de las comunicaciones"

- OSORIO Meléndez, A. Hugo "Políticas de Información y Derecho. Estudio Comparativo", Universidad Metropolitana de Ciencias de la Educación, Impresos Universitaria, Santiago de Chile 1997.

- $\quad$ RODRÍGUEZ VILLAFAÑE, Miguel Julio "Derecho a la información y conflictos con otros derechos humanos en Argentina". En "Los derechos de la información y de la comunicación. Panorama General", Asociación Iberoamericana del Derecho a la Información y de la Comunicación (AIDIC) y la Fundación Konrad Adenauer, Bogotá 2002.

- $\quad$ ROMERO UMLAUFF, Gustavo "El derecho humano de la información. Nociones generales y características", Colegio de Abogados de Lima, Año XCII № 1, Lima 2006.

Fecha de recepción : 30 de abril de 2019

Fecha de aceptación : 16 de junio de 2019 